\title{
The Iliotibial Band Transfer Restores Extensor Function after Quadricepsplasty for Knee Stiffness
}

\author{
Nguyen Ngoc Hung \\ Vietnam National Hospital of Pediatrics, Hanoi, Vietnam \\ Email: ngocyenhung@gmail.com
}

How to cite this paper: Hung, N.N. (2016) The Iliotibial Band Transfer Restores Extensor Function after Quadricepsplasty for Knee Stiffness. Open Access Library Journal, 3: e3048.

http://dx.doi.org/10.4236/oalib.1103048

Received: September 8, 2016

Accepted: September 26, 2016

Published: September 29, 2016

Copyright $\odot 2016$ by author and Open Access Library Inc.

This work is licensed under the Creative Commons Attribution International

License (CC BY 4.0).

http://creativecommons.org/licenses/by/4.0/

\begin{abstract}
Introduction: Retractile fibrosis of the quadriceps is a physical and social handicap in children, and often results from a past history of quadriceps intramuscular injection. The aim of this study was to evaluate the therapeutic results of fibrous quadriceps treated by distal quadricepsplasty using a transferring Iliotibial band (TITB) to prevent kin necrosis by Incision Z-Plasty. Materials and Methods: This is a descriptive retrospective 21-year study from 1984 to 2005, including 103 children (113 knees) less than 9 years old. Clinical were: all of patients knee flexion loss of motion $113(100 \%)$, without associated Genu recurvatum or Dislocation of the patella. Results: The pre-operative range of flexion varied from $5^{\circ}$ to $32^{\circ}$ with a mean range of $22.5^{\circ}$. The post-operative range was $75^{\circ}$ to $140^{\circ}$. The improvement in the range of flexion varied from $5^{\circ}$ to $140^{\circ}$ with a mean gain of $95^{\circ}$. At the final follow-up, the mean active flexion was $123.5^{\circ}$ ( 85 to 140 ). The final mean gain in movement was $97.6^{\circ}$ (25 to 135$)$. The mean pre-operative $\mathrm{ROM}$ was $37.9^{\circ}\left(0^{\circ}\right.$ to $\left.35^{\circ}\right)$. The mean ROM achieved at operation was $115.9^{\circ}\left(75^{\circ}\right.$ to $\left.140^{\circ}\right)$. Mean flexion ROM after surgery was $77.7^{\circ}$. Mean flexion increased from $77.7^{\circ}$ to $108.5^{\circ}$ following postoperative rehabilitation or a mean gain of $30.7^{\circ}$. Author was performed Incision Z-Plasty for 34 knees, all of them (100\%) with good result, and without incision necrosis. Conclusion: Quadriceps contracture is a condition quadriceps is contracted due to various causes. Various surgical options are available based on location of contracture, age, cause and duration of the contracture. Transfering Iliotibial band to Quadriceps after Quadripsplasty and Incision Z-Plasty with postoperative good result.
\end{abstract}

\section{Subject Areas}

Orthopedics, Pediatrics

\section{Keywords}

Retractile Fibrosis of the Quadriceps, Plasty, Child, Quadriceps Contracture, Transferring Iliotibial Band 


\section{Introduction}

Infantile quadriceps retraction is a condition first described in 1961 by Hnevkovsky [1]. During the following years, many papers concerning the condition were published. At first, quadriceps retraction was considered as a congenital disease. Todd was the first to emphasize the relationship between infantile quadriceps retraction and intramuscular injections [2]. By 1964, it was generally thought that the disease had an iatrogenic cause [3] [4].

Quadriceps muscle retraction follows muscle adherences induced by intramuscular injections into the anterolateral aspect of the thigh during the newborn period and early childhood [2] [4]-[6]. The first overt signs appear by the age of 2 years. Affected children are usually born prematurely and require several hospital admissions during the first 6 months of life, when they receive intramuscular antibiotic injections (most commonly penicillin or aminoglycosides [7]-[9].

Quadriceps myofibrosis is a clinical entity found in infants and young children which is characterized by alterations in the normal extensor mechanism of the knee joint resulting from fibrofatty replacement of the quadriceps muscles. It had been thought to occur as an idiopathic or congenital condition [10] [11], but later it was regarded as an iatrogenic sequela of multiple injectionst [12] [13]. Myofibrosis from injections has also been reported to occur in other muscles [14]-[17].

Limping, walking with stiff knees, and restricted knee flexion after multiple injections of antibiotics into the quadriceps muscle in infants and young children have been reported over the past 50 years, predominantly in Asian and African countries [1] [18]. Common sites for intramuscular injections are the gluteus medius, deltoid, vastus lateralis, and rectus femoris muscles. Although reports of impaired walking exist as a result of thigh muscle injections, these sites are still recommended in current practice guidelines [19] [20]. Skin dimples at the front and the lateral aspect of the thigh indicated a history of intramuscular injections of antibiotics in early childhood, confirmed by the parents. Knee flexion less than $45^{\circ}$ causes problems in gait and hindrance in day to day activities [21]. This results in severe disability and individual as a whole especially in country like in Asian and African countries where people sit on floor and squat for various purposes like working in the farms or for toilet.

Three methods of treatment were used: conservative, distal quadricepsplasty, and proximal release. Several methods of quadricepsplasty have been described such as the Thompson and Judet techniques and their modifications [22] [23], and Proximal release in the early stage and distal release in the late stage are the recommended treatments [24]. Distal quadricepsplasty such as the Thompson or V-Y Flaps, should not be performed in adults because it leads to significant permanent knee extension lag, especially when lengthening of the quadriceps tendon is required [22] [23]. This extension lag may occur in children as well, but because children are growing and constantly retensioning their quadriceps muscle, it may recover [25]. The preferable way of obtaining knee flexion is the Judet quadricepsplasty [23] [26]. This is a proximally based quadriceps muscle slide that addresses all elements of knee contracture. Various surgical options are 
available based on location of contracture, age, cause and duration of the contracture.

Several methods of quadricepsplasty have been described such as the Thompson and Judet techniques and their modifications [27] [28]. The most frequent complications were skin necrosis and active extension lag after the Payr-Thompson procedure. Thompson's quadricepsplasty may be complicated by skin necrosis and loss of full extension [26] [29]-[31].

We retrospective long time follow-up after lengthening of the rectus femoris for Payr-Thompson procedure with transfer Iliotibial band restores extensor function and incision plasty prevent skin necrosis

\section{Materials and Methods}

A retrospective study was carried out to evaluate the results of surgical techniques performed from Decembet 1984 to August 2005 in 112 patients (158 knees) with knee stiffness. The operations were performed by single surgeon (Author) and the evaluation by three independent orthopaedic surgeons, who were not members of the department.

Informed consent was obtained from all participants. The study had the approval of the Ethical Review Com-mittee of our Institute and was carried out in accordance with the tenets of the Declaration of Helsinki.

They were operated separating the adherence between the vastus intermedius tendon and the rectus femoris tendon. Next, dividing the vastus intermedius tendon at the musculotendinous junction, $5 \mathrm{~cm}$ above the patella. If knee flexion $>90^{\circ}$ was not achieved, the rectus femoris was detached $2 \mathrm{~cm}$ above the superior border of the patella, two tendons, the vastus intermedius, and the rectus femoris, being sewn together according to Nguyen $\mathrm{NH}$ et al [6]. When the rectus femoris was lengthened or divided it was as a last resort for gaining flexion, because that procedure diminishes the power of extension of the knee postoperatively [29]. The patients were excluded from the study due to be knee stiffness with genu recurvatum or knee stiffness with Dislocation of the patella. There were 9 patients ( 12 knees) were lost to follow-up before the end of this study. The remaining 103 patients (113 knees) formed the basis of this study; there were 71 women $(68.9 \%)$ and 32 men (31.1\%). Thirty-one of the children (30.1\%) were born prematurely. There an average age at time operation were 37 months (12 to 81 months). Unilateral involvement was most common, with the left knee affected in 30 patients (29.1\%) and the right knee affected in 63 patients (61.2\%). Both the knees were involved in 10 patients (9.7\%). In 11 patients, the condition was also associated with the triceps and deltoid muscles, likely due to a similar process.

Preoperatively, information was obtained about the type and quantity of medication that had been injected, history of trauma, age at the onset of symptoms, duration of symptoms, associated contractures, localized skin changes, pain, cosmetic problems, and changes in functional activities.

Their parents were usually aware of the difficulty their child had in squatting, kneeling, sitting cross-legged, running, or climbing stairs.

Normal knee motion has been described as 0 degrees of extension to 130 degrees of 
flexion [8]. Knee stiffness when the patient have restriction of knee flexion. The range of movement (ROM) of the knee was measured at each visit by the surgeon who had performed the operation (SBH) using a goniometer with $30 \mathrm{~cm}$ movable arms and a scale marked in $1^{\circ}$ increments. The range of knee movement was measured first with the hip flexed and then with it extended. The stationary arm of the goniometer was placed parallel to the long axis of the femur along a line extending from the greater trochanter to the lateral condyle, and the movable arm was placed parallel to the long axis of the fibula, between the head of the fibula and the lateral malleolus.

To measure Extension Lag (EL) the examiner placed a clenched fist under the patient's heel so that the extremity was clear of the table. The patient was then asked to tighten the quadriceps muscle by pushing his knee down toward the table. With his other hand, the examiner palpated the quadriceps tendon at the superior pole of the patella to ensure that the muscle was exerting a force [32].

The quadriceps always was wasted and felt firm and fibrous. The patella was small and high. In a number of patients there were injection scars, including a dimple on the skin in the mid-part of the thigh which became more prominent with flexion of the knee (Figure 1). This was caused by adherence of the muscle to the skin and indicated the site of abscess formation following the intramuscular injection.

\subsection{Operative Technique}

We performing operation separate three Variant:

Variant 1 (54 knees): The operation separating the adherence between the vastus intermedius tendon and the rectus femoris tendon. Next, dividing the vastus intermedius tendon at the musculotendinous junction, $5 \mathrm{~cm}$ above the patella. If knee flexion $>90^{\circ}$ was not achieved, the rectus femoris was detached $2 \mathrm{~cm}$ above the superior border of the patella. The proximal tendinous end of the vastus intermedius and the distal portion of the rectus femoris tendon are then overlapped and sutured together with the knee in $60^{\circ}$ of flexion [6].

Variant 2 (59 knees): Transfering IlioTibial band to position of the proximal tendinous end of the vastus intermedius and the distal portion of the rectus femoris tendon have been overlapped and sutured together with the knee in $20^{\circ}$ of flexion.

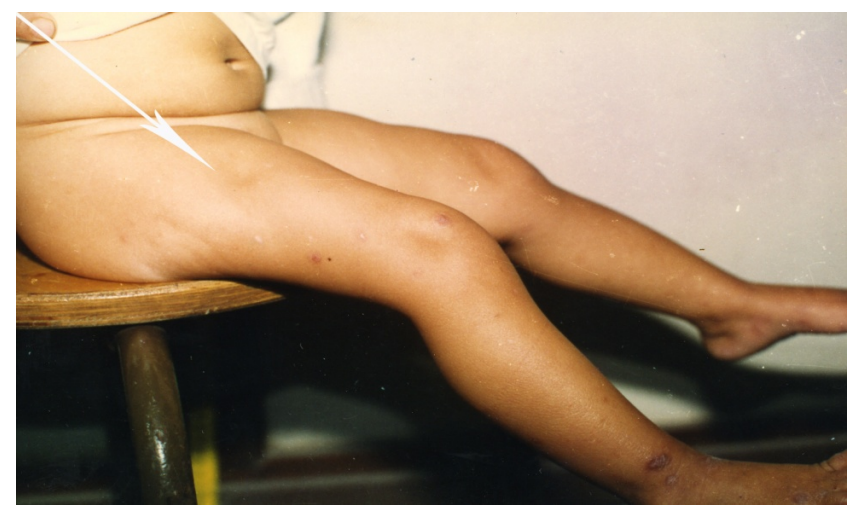

Figure 1. Dimple in the anterolatral aspect of the thigh. 


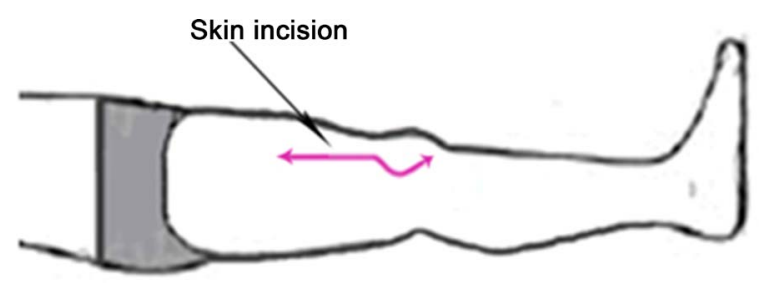

Figure 2. Skin incision.

Variant 3 (29 knees): The incisions are unable closed with the knee in $>60^{\circ}$ of flexion. Performing incision single Z plasty.

\subsection{Patient Positioning}

The patient was positioned supine on a standard operating table, placed under general anesthesia, with a sandbag behind the knee to keep it in between $5^{\circ}$ and $10^{\circ}$ of flexion; the anterolateral part of the thigh was exposed. We used the anterolateral approach that extended from the mid-third of the thigh to the tibial tuberosity, and a slightly curved lateral border of the patella (Figure 2). The subcutaneous tissues were undermined sufficiently to create a skin flap that would allow us to expose the quadriceps muscle, the iliotibial tract. The incision continued proximally, lateral to the rectus femoris tendon, thus fully releasing the vastus lateralis and vastus medialis. Any abnormal attachments of the iliotibial tract to the patella and to the lateral capsule were incised longitudinally. It was always necessary to detach the insertion of the vastus lateralis from the patella, separating it from the rectus femoris medially and the iliotibial tract laterally, then mobilizing it proximally (Figure 2). The vastus medialis was released for a distance of 2 - 8 $\mathrm{cm}$ in an attempt to obtain a straight-line pull.

Variant 1: Lengthening the rectus femoris and vastus intermedius. We separated the adherence between the vastus intermedius tendon and the rectus femoris tendon. Next, we divided the vastus intermedius tendon at the musculotendinous junction, $5 \mathrm{~cm}$ above the patella. We performed knee flexion; If knee flexion $>90^{\circ}$ was not achieved, the rectus femoris was detached $2 \mathrm{~cm}$ above the superior border of the patella, two tendons, the vastus intermedius, and the rectus femoris, being sewn together with using No. 2 Ethibond sutures while the knee was flexed at $60^{\circ}$ (Figure 3) (variant 2). Finally, the remaining vastus intermedius muscle was sutured to the rectus femoris.

Variant 2: The same Variant 1 and transferring the iliotibial band. Extending incision in Variant 1 to just below the greater trochanter $4 \mathrm{~cm}$. The edges of the skin are then reflected on each side by blunt dissection, fully exposing the fascia lata from the middle of the thigh to the inferior edge of the lateral surface. It is important that the reflection of the skin should be sufficiently wide to expose the insertion of the gluteus maximus into the fascia lata. A strip about half an inch in width is dissected free, to the part of the iliotibial band which is well defined. Beginning about two inches above the knee joint, the strip of the fascia lata which includes the iliotibial band is widened gradually toward the upper third of the thigh. Next step, transfer end of the iliotibial band to site the vastus intermedius and the distal portion of the rectus femoris tendon are overlapped and sutured together with the knee in $20^{\circ}$ of flexion by No. 2 Ethibond (Figure 4). 


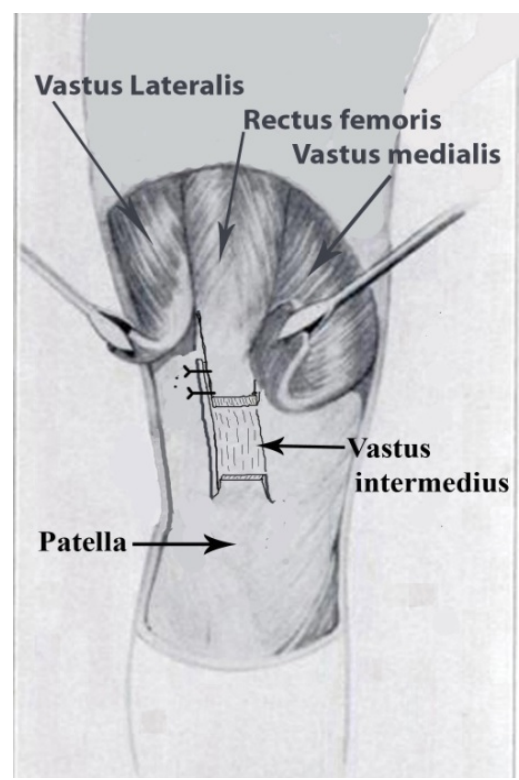

Figure 3. The vastus intermedius and the rectus femoris, being sewn together together with the knee in $60^{\circ}$ of flexion by No. 2 Ethibond [6].

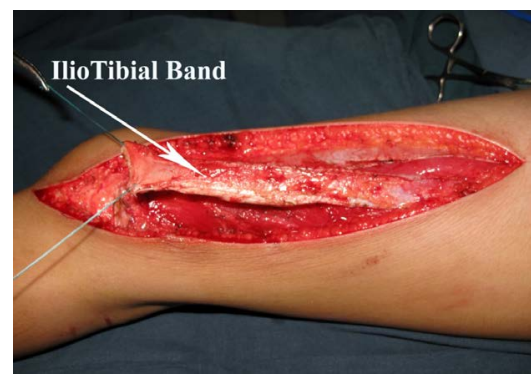

(a)

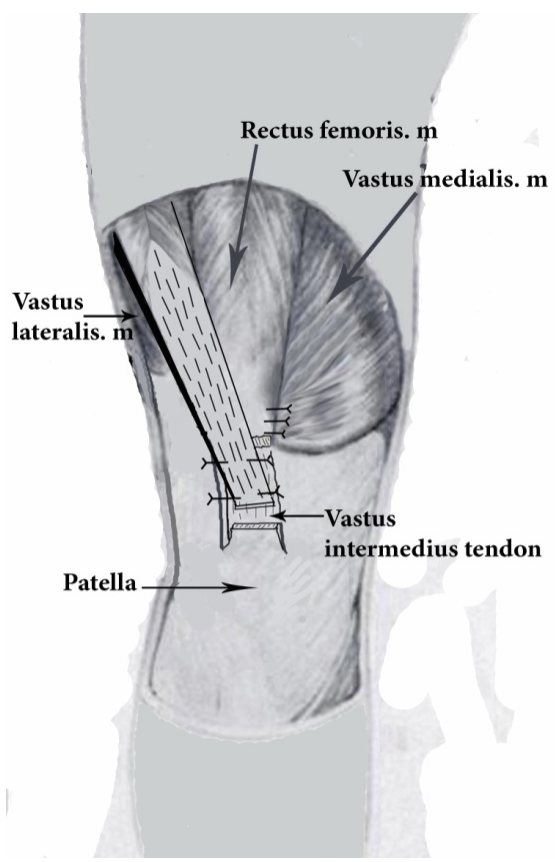

(b)

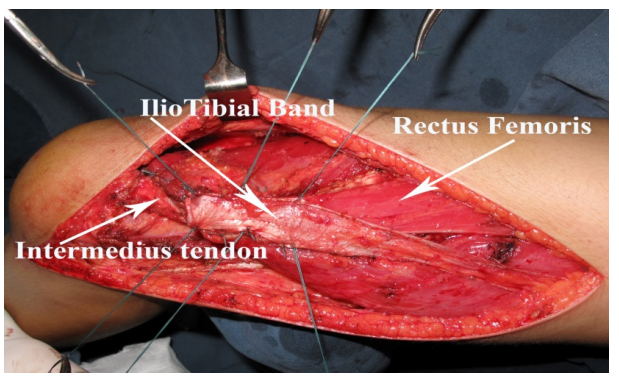

(c)

Figure 4. (a) Expose Iliotibial Band; (b) (c) Transfer end of the iliotibial band to site the vastus intermedius and the distal portion of the rectus femoris tendon are overlapped and sutured together with the knee in $20^{\circ}$ of flexion.

Variant 3: The incisions are unable closed with the knee in $60^{\circ}$ of flexion. Performing incision Z plasty. We performing Single Z-Plasty, the transposition of two triangular flaps. The incisions are designed to create a $Z$-shape with the central limb aligned with the part of the incision that needs lengthening 2 inchs. The traditional $60^{\circ}$ angle Z-plasty will give a theoretical lengthening of the central limb of $75 \%$ [33]. Single 
z-plasties can be used (Figures 5-7).

One surgeon (the author) performed all operations.
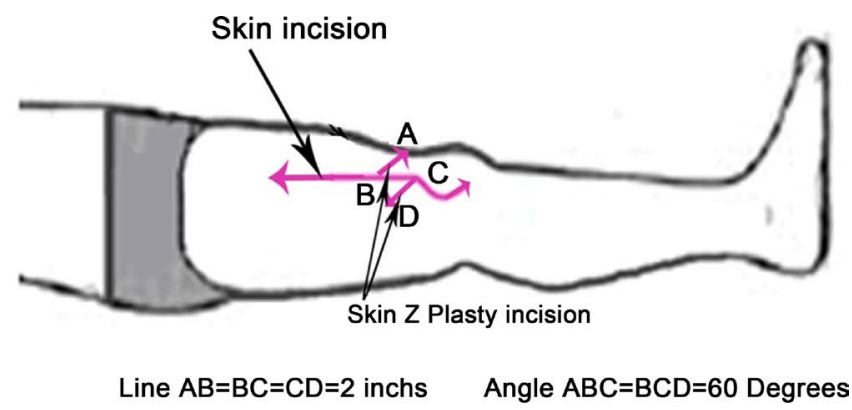

(a)

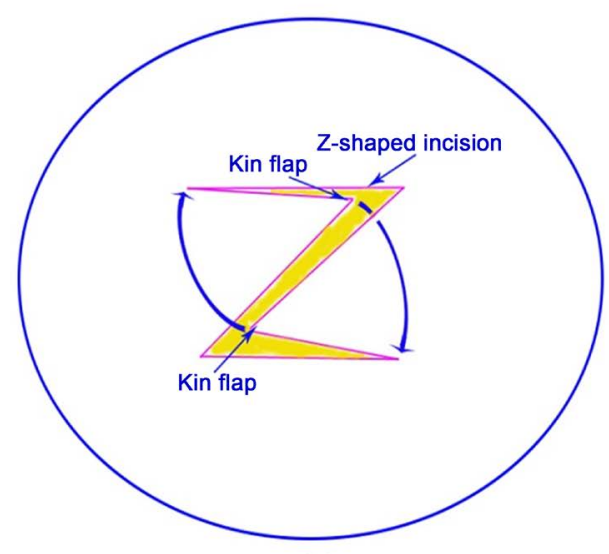

(b)

Figure 5. (a) Skin Z plasty incision; (b) Rotation of Skin flap.

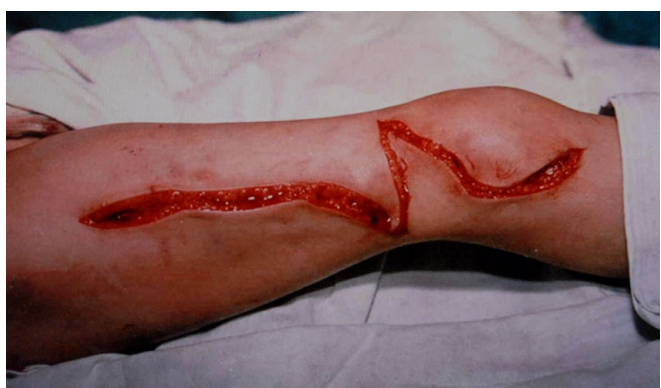

Figure 6. Skin Z plasty incision intra Operation.

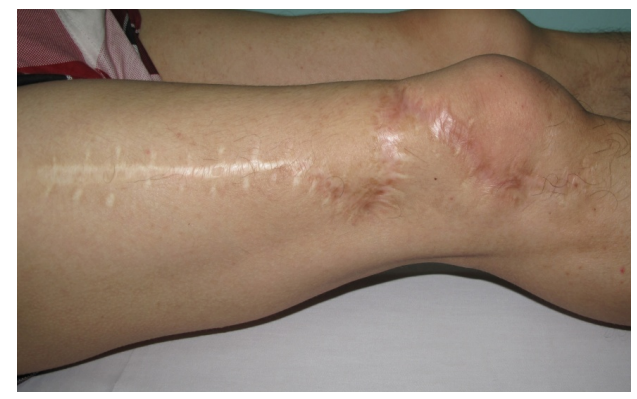

Figure 7. Operatively, Skin Z plasty in 19 years, 5 months. 


\subsection{Postoperative Rehabilitation}

Postoperatively, the knee was placed in a double-capsule cast with the knee flexed at $60^{\circ}$. This was a long-leg cast (Figure 7). The cast could be removed easily for knee mobilization physical therapy and then be replaced after-wards. Thereafter, the knee is kept in full extension during the night and exercised during the day on counterbalanced slings. The patient was allowed out of bed 1 day after the operation. Static quadriceps exercises and gentle knee movements (passive range of motion not $>60^{\circ}$, equal knee flexed at $60^{\circ}$ were permitted, but more vigorous or extensive movements were discouraged during the first week, in order to minimize effusion or bleeding. In the first 2 weeks, a passive range of motion up to $60^{\circ}$ and under $90^{\circ}$ was performed with the physiotherapist. After 2 weeks, the range of motion was increased up to $90^{\circ}$ (note: the limitations on the range of motion and weight-bearing counted only for the exercise periods, and outside of the exercise times, the cast had to be worn). After 3 weeks, the range of motion was increased to normal. The cast was removed after about 6 weeks, but without weight-bearing. After-wards, patients were allowed to bear $25 \%$ of their body weight for the first 2 weeks, and $50 \%$ of their body weight in the following 2 weeks. Full weightbearing was allowed between the fourth and sixth weeks after cast removal.

\subsection{Critical Results}

The final results were assessed by Judet's criteria [26] with knee: excellent, if flexion was greater than $100^{\circ}$; good, from $81^{\circ}$ to $100^{\circ}$; fair, from $50^{\circ}$ to $80^{\circ}$; and poor, if less than $50^{\circ}$ flexion, and addition of extension lag with persistent extension lag of $15^{\circ}$, it did not interfere with the activities of daily living or work [37]. The patients with poor results always had a considerable lag in extension. Any patients with full flexion but poor power of the quadriceps muscle (graded less than 2) were also included in the group with poor results [33] (Table 1).

The patients with poor results always had a considerable lag in extension. Any patients with full flexion but poor power of the quadriceps muscle (graded less than 2) were also included in the group with poor results [35].

\subsection{Follow-Up}

All patients were examined and evaluated by three other doctors, at follow-up times of 3, 6 weeks, 3, 6 months, 1 year, and afterwards every year. At final follow-up, after an average period of 22 years, 4 months (range 19 years, 6 months to 31 years, 8 months).

There were 103 patients, the mean age of the patients at time operation was 37 months (12 to 81 months). The mean follow-up was 22 years, 4 months (range 19 years, 6 months to 31 years, 8 months).

\subsection{Statistical Analysis}

The paired-samples $t$-test was used for comparison between the pre-operative and the final ROM of the knee. Univariate regression analysis was performed to determine whether there was a significant association between each of the pre-operative and 
Table 1. The final results were assessed by Judet's criteria [26], and addition of extension lag with persistent extension lag.

\begin{tabular}{ccccc}
\hline & Excellent & Good & Fair & Poor \\
\hline Flexion & $>100^{\circ}$ & $>80^{\circ}-\leq 100^{\circ}$ & $\geq 50^{\circ}-\leq 80^{\circ}$ & $<50^{\circ}$ \\
Extension lag & $0^{\circ}-\leq 5^{\circ}$ & $>5^{\circ}-\leq 15^{\circ}$ & $>15^{\circ}-\leq 30^{\circ}$ & $>30^{\circ}$ \\
\hline
\end{tabular}

operation-related variables and the final gain in flexion. All analyses were performed with SPSS, version 12.0 (SPSS Inc., Chicago, Illinois) and a p-value $<0.05$ was considered significant.

\section{Results}

There were 103 patients in this study, the mean age of the patients at time operation was 37 months ( 12 to 81 months). The mean age at final follow-up was 23 years, 2 months old (range, 24 years, 6 months to 32 years, 7 months old). The mean follow-up was 22.4 years (19.6 - 31.8 years).

The age of 4 - 6 years (58.3\%) was the most affected. Onset of contraction after injection was 6 months (range: 3 - 15 months).

Thigh amyotrophy was found in all cases of stiffness. In the case of unilateral knee stiffness, the mean difference between thighs' circumferences was $3.65 \mathrm{~cm}$ (range: 2.2 $5.5 \mathrm{~cm}$ ).

The Eighteen of patients there were injection scars, including a dimple on the skin in the mid-part of the thigh which became more prominent with flexion of the knee (Figure 8). This was caused by adherence of the muscle to the skin and indicated the site of abscess formation following the intramuscular injection.

The main complaint of these patients was inability to squat, which is a great physical and social handicap in the East. In one patient the presenting symptom was habitual lateral dislocation of the patella.

The pre-operative range of flexion varied from $5^{\circ}$ to $32^{\circ}$ with a mean range of $22.5^{\circ}$. The post-operative range was $75^{\circ}$ to $140^{\circ}$. The improvement in the range of flexion varied from $5^{\circ}$ to $140^{\circ}$ with a mean gain of $95^{\circ}$.

At the final follow-up, the mean active flexion was $123.5^{\circ}$ ( 85 to 140 ). The final mean gain in movement was $97.6^{\circ}$ (25 to 135 ).

The mean pre-operative ROM was $37.9^{\circ}\left(0^{\circ}\right.$ to $\left.35^{\circ}\right)$. The mean ROM achieved at operation was $115.9^{\circ}\left(75^{\circ}\right.$ to $\left.140^{\circ}\right)$. Mean flexion ROM after surgery was $77.7^{\circ}$. Mean flexion increased from $77.7^{\circ}$ to $108.5^{\circ}$ following postoperative rehabilitation or a mean gain of $30.7^{\circ}$.

The quadriceps muscle testing scores were at least 3/5.

\subsection{Motion}

At the time of the final follow-up, the average maximum amount of flexion was $115^{\circ}$ (range, $85^{\circ}$ to $140^{\circ}$ ), indicating a mean flexion gain of $86^{\circ}$ (range, $44^{\circ}$ to $126^{\circ}$ ).

In our series, the mean maximum flexion was $112.5^{\circ}\left(55^{\circ}\right.$ to $\left.150^{\circ}\right)$ and the mean 


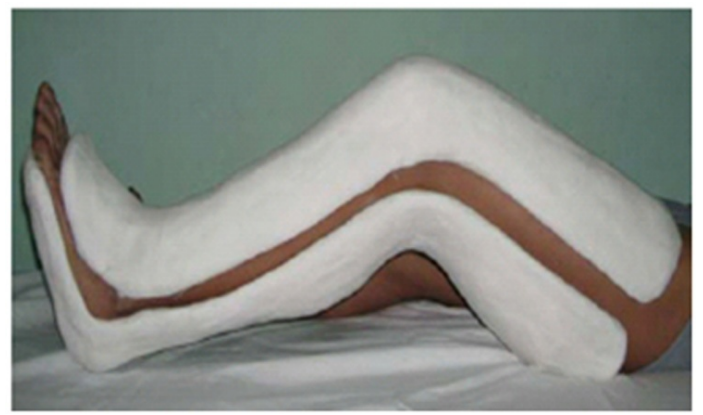

Figure 8. Knee was placed in a double-capsule cast with the knee flexed at $60^{\circ}$.

ROM was $110.4^{\circ}\left(55^{\circ}\right.$ to $\left.150^{\circ}\right)$, with $70.3^{\circ}\left(5^{\circ}\right.$ to $\left.110^{\circ}\right)$ of mean flexion gain at a mean follow-up of 22.6 years.

We performing Incision Z-Plasty for 34 knees, all of them (100\%) with good result, and without incision necrosis.

\subsection{Complications}

There were not skin necrosis or sutures anomalies after operation. four cases (3.5\%) of femoral metaphyseal fractures occurred during rehabilitation exercises with the arrest of the process and immobilisation in flexion by plaster In terms of outcome, all patients had a rating of power in the quadriceps muscle above $3 / 5$ at the end of the rehabilitation. There were 21 cases (18.6\%) of poorly looking postoperative scars; with Hematoma in $1(0.9 \%)$ and without Femoral nerve tear, Quadriceps tendon tear. Loss of active extension 2 knees with $>30^{\circ}$ in Variant 1.

\section{Discussion}

The contraction of the quadriceps in childhood may be congenital or secondary to a different variety of reasons. This study discusses the femoral quadriceps muscle sclerosis, induced by injection in the thigh muscle and sclerosis resulting in a progressive painless limitation of knee flexion [26]. All children had suffered from serious illnesses since the first weeks of life for which they had received intramuscular thigh injections. A thigh dimple was noticed in all patients [4].

The mechanism by which these injection induced contractures develop is speculative. In the case of infants and babies the muscle mass is small and, for most of those babies included in the study who were born prematurely, the muscle mass must have been even smaller [36] Due to the volume of injected drugs, the compression of muscles and capillaries can result in significant muscle ischemia [13]. The experimental trauma of a single intramuscular injection seems to cause disruption of muscle fibers with local necrosis and subsequent muscle fibrosis [37]; local drug toxicity may, also, play an important part [10]. It is interesting to point out that the damage to the muscle after injection is different from the damage caused by vascular injury. Unlike the ellipsoidal forearm heart attack [38], where Volkman's contracture is immediately obvious, after the injection therapy there is a considerable delay before contractures develop in the thigh. 
In our study, the age at admission varied from 1 year to 9 years.

Williams [39] has suggested that injection induced contractures may be related to unequal growth of muscle and bone. At first the healthy distal muscle fibers can compensate for the bone growth and, as a result, there is no visible effect on the knee for several years after the injection treatment. Subsequently, it reaches a point where the healthy muscle can no longer lengthen in proportion to the bone growth and contracture becomes apparent. The differentiated growth between bone and muscle cannot be the only one responsible for any worsening of the patient's condition. If contractures of this type are left untreated, secondary changes may occur in soft tissues, cartilage and bone of the neighboring joint [39]. Some authors have observed that good results are achieved through the surgery of reinsertion of thigh muscle for mobilization the knee.

An accessory muscle is usually asymptomatic, and any symptoms are due to its potential for nerve compression [40] [41] or localised compartment syndrome during exercise [5]. In some cases it can mimic a soft-tissue tumour [42]-[44]. We believe that the progressive restriction of knee flexion in our patient was due to the lack of elasticity of the accessory muscle, which became a tether as the femur grew. The muscle belly was short in proportion to its long tendon [45].

The quadricepsplasty is a major operation; its ability to successfully achieve knee flexion range depends both on the surgeon as well as the patient. To achieve a successful outcome, preparation begins in the preoperative period with patient education on knee exercises; continues in the peroperative period by use of meticulous sharp dissection and hemostasis, and is followed up postoperatively by adhering to a strict postoperative rigourous physiotherapy protocol in conjuction with sound will and the ability of the patient so as to prevent quadriceps inhibition and allow toning and strengthening of the quadriceps and hamsrings muscles. The patient must be sensitized about mild extensor lag which he may have on follow up.

Of the various techniques for quadricepsplasty, Thompson's and Judet's have been the most popular. The most distinct difference between the two techniques is the site of release of the quadriceps mechanism: release at the site of insertion in Thompson's technique.

As a result, Judet's quadricepsplasty requires a much more extensive dissection and precludes the use of a tourniquet. Thompson's technique, on the other hand, has inherent weaknesses, such as delayed wound healing, infection, and an extension lag as the rectus femoris is isolated from the rest of the quadriceps through an anterior midline incision [46] [47] which was the main reason for seeking a modification of the technique and Proximal release in the early stage and distal release in the late stage are the recommended treatments [21] (See Table 2).

The Thompson quadricepsplasty [51] and its modification [23] involve stripping the rectus femoris entirely off the vastus muscles, releasing the vastus medialis and vastus lateralis from their patellar insertion, and lengthening the rectus femoris when necessary. These procedures may result in substantial weakness of the extension mechanism and an extension lag [19] [23]. Extension lag following Quadricepsplasty has been widely reported high rate from $8^{\circ}$ to $61.1^{\circ}$ in the literature [19] [22] [23] [36] [47]-[51]. Lengthening of the rectus femoris has been considered to be the causative factor [19]. 
Table 2. Knee flexion.

\begin{tabular}{cccc}
\hline & \multicolumn{3}{c}{ Average (Range) } \\
\hline V 1 (54 knees) & V 2 (59 knees) & Total $(113$ knees $)$ \\
\hline Knee flexion after 6 Months & $76^{\circ}\left(65^{\circ}-135^{\circ}\right)$ & $71^{\circ}\left(60^{\circ}-130^{\circ}\right)$ & $73^{\circ}\left(60^{\circ}-135^{\circ}\right)$ \\
Knee flexion after 1 year & $93^{\circ}\left(78^{\circ}-140^{\circ}\right)$ & $90^{\circ}\left(82^{\circ}-140^{\circ}\right)$ & $92^{\circ}\left(78^{\circ}-140^{\circ}\right)$ \\
Knee flexion after 2year & $104^{\circ}\left(85^{\circ}-140^{\circ}\right)$ & $115^{\circ}\left(90^{\circ}-140^{\circ}\right)$ & $109^{\circ}\left(85^{\circ}-140^{\circ}\right)$ \\
Knee flexion after 3 year & $113^{\circ}\left(94^{\circ}-140^{\circ}\right)$ & $118^{\circ}\left(98^{\circ}-140^{\circ}\right)$ & $115^{\circ}\left(94^{\circ}-140^{\circ}\right)$ \\
Knee flexion end follow-up & $121^{\circ}\left(120^{\circ}-140^{\circ}\right)$ & $128^{\circ}\left(125^{\circ}-140^{\circ}\right)$ & $125^{\circ}\left(120^{\circ}-140^{\circ}\right)$ \\
\hline
\end{tabular}

Knee flexion were improved from mean $73^{\circ}\left(60^{\circ}-135^{\circ}\right)$ in postoperative 6 months to $125^{\circ}\left(120^{\circ}-140^{\circ}\right)$ end follow-up.

Table 3. Extension lag.

\begin{tabular}{ccccc}
\hline & \multicolumn{2}{c}{ Variant 1 (54 knees) } & \multicolumn{2}{c}{ Variant 2 (59 knees) } \\
\cline { 2 - 5 } & Number $(\%)$ & Average (Range) & Number (\%) & Average (Range) \\
\hline Extension lag after 6 Months & $22(40.7)$ & $38^{\circ}\left(25^{\circ}-46^{\circ}\right)$ & $21(35.6 \%)$ & $36^{\circ}\left(27^{\circ}-41^{\circ}\right)$ \\
Extension lag after 1 year & $18(33.3)$ & $28^{\circ}\left(21^{\circ}-37^{\circ}\right)$ & $17(20.8)$ & $26^{\circ}\left(20^{\circ}-32^{\circ}\right)$ \\
Extension lag after 2 year & $14(25.9)$ & $23^{\circ}\left(18^{\circ}-35^{\circ}\right)$ & $6(10.2)$ & $15^{\circ}\left(12^{\circ}-18^{\circ}\right)$ \\
Extension lag after 3 year & $9(16.7)$ & $21^{\circ}\left(14^{\circ}-35^{\circ}\right)$ & $3(5.1 \%)$ & $10^{\circ}\left(12^{\circ}-15^{\circ}\right)$ \\
Extension lag end fellow-up & $4(7.8)$ & $19^{\circ}\left(14^{\circ}-34^{\circ}\right)$ & $2(3.4)$ & $9^{\circ}\left(8^{\circ}-10^{\circ}\right)$ \\
\hline
\end{tabular}

Extension lag were improved from $38^{\circ}$ to $19^{\circ}$ in variant 1 , and $36^{\circ}$ to $9^{\circ}$ in variant 2 . At end follow-up, Extension lag mean $19^{\circ}, 2$ knees with $>30^{\circ}$ in Variant 1 ; and Extension lag mean $9^{\circ}$ in Variant 2.

All patients with an extension lag had gradual improvement of extension power and reduction in the lag with quadriceps stretching and strengthening exercises. The extension lag resolved between three months and ten years postoperatively [23] [33] [41] [52][56]. In this study, still extension lag $34^{\circ}$ in two cases post-operative 21 years (See Table 3 ).

Despite several complications, most of our patients achieved a meaningful improvement of knee flexion following quadricepsplasty after two or more years of follow-up. We recommend that surgeons should consider rectus femoris lengthening if satisfactory knee flexion cannot be obtained with gentle passive manipulation after adhesiolysis around the knee joint in order to avoid rupture of the extensor mechanism. If full extension and flexion cannot be maintained, full extension should be the first goal [29].

We agree with Hesketh's opinion that at operation Thompson's original technique [60]. It is important not to use a tourniquet, because many large vessels are cut during the dissection, particularly in the parapatellar area, and these must be seen and secured. Diathermy is most useful for dividing the vasti and for dealing with the many small bleeding points, especially in heavily scarred areas. In two early cases blood had to be given, but with careful haemostasis this is no longer found necessary. Haematoma could greatly delay progress.

We agree with Gbenou's [55] opinion that when lengthening Quadriceps The proximal tendinous end of the vastus intermedius and the distal portion of the rectus femo- 
ris tendon are then overlapped and sutured together with the knee in $60^{\circ}$ of flexion to reduce the risk of creating an extension lag and even in the cases where there was $90^{\circ}$ peroperative flexion, did not perform V-Y plasty of rectus femoris [21]. According to Wang et al. [56] suture elongation plasty was in knee flexion position of $90^{\circ}$, may result in substantial weakness of the extension mechanism and an extension lag.

Techniques for reconstruction of the extensor mechanism of the knee have been described since the end of the 19th century [57] with modern techniques derived from those originally developed in patients with poliomyelitis [58] [59].

The requirement for functional restoration of extension of the knee is uncommon, but the absence of controlled active extension is a potentially devastating problem, occurring after resection of the quadriceps muscle in patients with sarcoma, femoral nerve dysfunction, trauma, poliomyelitis and chronic complex tendon ruptures [59] [60]. A number of other muscle transfers have been described, but functional outcomes for these have not been independently reported. These include transfer of tensor fascia lata described in 1933 by Ober [61].

In 1925 Spitzy suggested transposition of the iliotibial band to the patella as a treatment for quadriceps paralysis following poliomyelitis [62] [63]. His proposal was based on the fact that the tractus with the tensor fasciae muscle extends over two joints, being situated anteriorly of the axis of movement of the hip and posterolaterally of the axis of the knee-joint. When the hip-joint is extended, the tractus with its tensor muscle thus stretches and stabilizes the knee. He also pointed out, as did Erlacher [64], that the tensor fasciae latae muscle often escapes paralysis wen when the flexors of the thigh are affected. In 1933, Ober pointed out the risk of recurvatum following transposition of the hamstring muscles and suggested that the tensor fasciae latae and sartorius be employed instead [61]. In 1926, Yount gave indications for transposition of the tractus ilio-tibialis [65] and, in 1938, presented his series of 16 cases in which good results had been obtained [66]. In one half of these, the biceps femoris had been used in combination with the tractus. Apart from reports on isolated cases [67] [68], no other series with transposition of the tractus ilio-tibialis as the sole treatment of quadriceps paralysis has been published. In 1940, Debrunner [69] pointed out that the muscular power needed for transfer of the stabilizing power of the knee-joint to the ligaments is small. We performed transferring iliotibian band in 59 knees. Compared Extension lag show Extension lag were improved from $38^{\circ}$ to $19^{\circ}$ in variant 1 , and $36^{\circ}$ to $9^{\circ}$ in variant 2 . At end follow-up, Extension lag mean $19^{\circ}, 2$ knees with $>30^{\circ}$ in Variant 1 (Figure 9); and Extension lag mean $9^{\circ}$ in Variant 2. (Figure 10); The Results of Surgical Quadricepsplasty and it was transfered Iliotibal band shown end result accepted 100\% (See Table 4).

Their parents were usually aware of the difficulty their child had in squatting, kneeling, sitting cross-legged, running, or climbing stairs. In each case the affected leg had a dimple in the thigh, which deepened on forced flexion of the knee [70].

Gbenou et al. [55] and Shivaprasad et al. [71] used knee flexion gain and quality of walking as a measure of treatment outcome. Results were rated 'good' if flexion gained was above $90^{\circ}$, allowing normal gait and squatting, which is often essential for toileting 


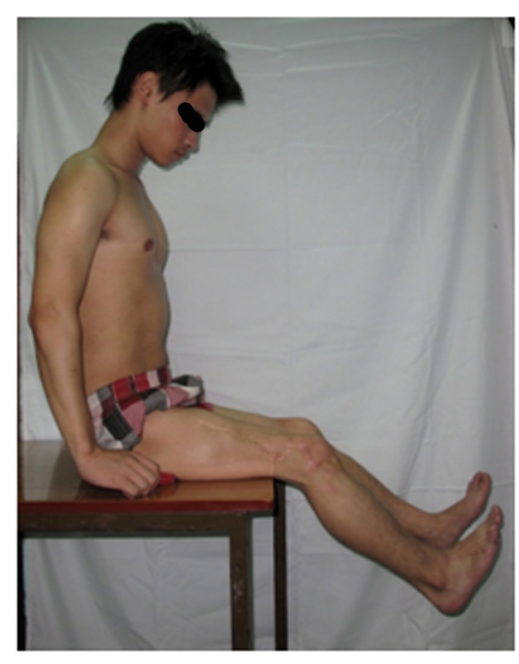

Figure 9. Extension lag $34.1^{\circ}$ in Variant 1.

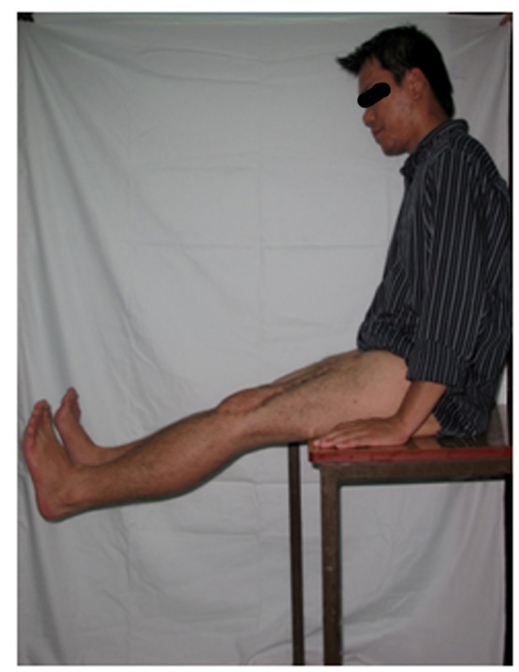

Figure 10. Extension lag $5.0^{\circ}$ in Variant 2.

Table 4. Lates results.

\begin{tabular}{cccc}
\hline & V 1 (54 knees) & V 2 (59 knees) & Total (113 knees) \\
\hline Excellent & $31(57.4 \%)$ & $47(79.7 \%)$ & $78(69.1 \%)$ \\
Good & $19(35.2 \%)$ & $12(20.3 \%)$ & $31(27.5 \%)$ \\
Fair & $2(3.7 \%)$ & 0 & $2(1.7 \%)$ \\
Poor & $2(3.7 \%)$ & 0 & $2(1.7 \%)$ \\
\hline
\end{tabular}

Accepted result 50 (92.6\%) in Variant 1; 59 (100\%) in Variant 2; 109 (96.5\%) in all patients. were Accepted result in V1 the same V2 (P Valuae: O.105455); but, Excellent V1 more than V2 (P Valuae: O.019132).

and farm in African and Asian countries. Results were considered 'acceptable' if flexion gained was between $45^{\circ}$ and $90^{\circ}$, normal gait was observed and a comfortable sitting position was achieved. Results were considered "poor" if flexion gained was less than $45^{\circ}$, associated with limping and uncomfortable sitting. 
Knee flexion of less than $45^{\circ}$ hampers the normal gait of the patient and causes problems in gait and hindrance in day to day activities [21] [72].

The Authors were in other country so in day to day activities and angle knee flexion and post-operative critical result were different (See Table 5, Table 6).

Effective wound healing is the basis of all surgery. When wounds do not heal the reason is generally obvious, and is usually associated with inadequate blood supply to the area. Haematoma, excessive tension, foreign body and irradiation all predispose to ischaemic necrosis and wound breakdown. In Thompson's technique uses an anterior midline incision and release at the site of origin in Judet's technique uses a long lateral incision [36]. Some authors have been modified incision and reported rate of kin necrosis after post-operation of the Quadricepsplasty from $13.2 \%$ to 67\% [23] [29] [30] [51] [52] [55] [60] [73].

We performed Incision Z-Plasty according to Principles of Plastic Surgery is Incisions should not transgress cavities or flexion creases. Because all linear scars contract, an incision in such sites will heal with webbing and tenting of skin across the hollow and cause contracture or limitation of full extension across joints. Incisions should therefore curve around the concavity or be closed in a fashion that achieves lengthening or relaxation of the line. Such a technique is Z-plasty. The transposition of two triangular flaps. The incisions are designed to create a $\mathrm{Z}$ shape with the central limb aligned with the part of the incision that needs lengthening or re-aligning. The traditional $60^{\circ}$

Table 5. Critial result.

\begin{tabular}{cccccc}
\hline & Judet [26] & Gbenou [55] & Petrea [36] & Mukherjee [32] & Hung (in this study) \\
\hline Excellent & Over $100^{\circ}$ & & Over $110^{\circ}$ & & $>100^{\circ}+\leq 5^{\circ} \mathrm{EL}$ \\
Good & $80^{\circ}-100^{\circ}$ & Over $90^{\circ}$ & $90-110^{\circ}$ & $90-135^{\circ}$ & $80^{\circ}-\leq 100^{\circ}+>5^{\circ}-\leq 15^{\circ} \mathrm{EL}$ \\
Satisfactory & $50^{\circ}-80^{\circ}$ & $45^{\circ}-90^{\circ}$ & & \\
Very poor & Sub 50 & Under $45^{\circ}$ & & \\
Moderate & & $70^{\circ}-90^{\circ}$ & \\
Fair & & & $45^{\circ}-90^{\circ}$ & $\geq 50^{\circ}-\leq 80^{\circ}+>15^{\circ}-\leq 30^{\circ} \mathrm{EL}$ \\
Poor & & Under $70^{\circ}$ & Under $45^{\circ}$ & $<50^{\circ}+>30^{\circ} \mathrm{EL}$ \\
\hline
\end{tabular}

EL: Extension Lag

Table 6. Compare Results of Surgical Quadricepsplasty and it was Transfered IlioTibal Band.

\begin{tabular}{cccccc}
\hline Author & Procedure & Exellent & Good & Fair & Poor \\
\hline Hněvkovsky (1961) [1] & Bennett's & $0 \%$ & $70 \%$ & $30 \%$ & - \\
Bos \& Chong (1976) [40] & Thompson's/Bennett's & $55 \%$ & $25 \%$ & $20 \%$ & - \\
Mukherjee \& Das (1968) [32] & Thompson's/Bennett's & $15 \%$ & $60 \%$ & $10 \%$ & $5 \%$ \\
Jackson \& Hutton (1985) [64] & Thompson's & $45 \%$ & $45 \%$ & $10 \%$ & - \\
Hung-Variant 1 (2016) & Payr's/Hung's & $57.4 \%$ & $35.2 \%$ & $3.7 \%$ & $3.7 \%$ \\
Hung-Variant 2 (2016) & Payr's/Hung's and TITB* & $79.7 \%$ & $20.3 \%$ & - & - \\
\hline
\end{tabular}

TITB*: Transfered Ilio Tibal Band 
angle Z-plasty will give a theoretical lengthening of the central limb of 75\% [34] Single or multiple z-plasties can be used. Specific modifications include the double-opposing z-plasty (sometimes called a "jumping man" flap) which can be useful for release of webbing of the medial canthus or release of 1 st web space contractures. We performing Incision Z-Plasty for 34 knees, all of them (100\%) with good result, and without incision necrosis.

\section{Conclusions}

Quadriceps contracture is a condition quadriceps which is contracted due to various causes. Various surgical options are available based on location of contracture, age, cause and duration of the contracture. Better results were obtained whenever surgery was done early and also helped in preventing secondary adoptive changes in soft tissues, cartilage and bones. Physiotherapy is the main stay in the post operative management not only in gaining maximum flexion but also in regaining active extension. Transfering Iliotibial band to Quadriceps after Quadripsplasty and Incision Z-Plasty with postoperative good result.

Limitations of this study included the following: Not all the included patients were followed to mature bones, and which is of critical importance, as the clinical, as well as radiographic results tend to vary with time.

\section{References}

[1] Hněvkovsky, O. (1961) Progressive Fibrosis of the Vastus Intermedius in Children. The Journal of Bone \& Joint Surgery, 43B, 318-325.

[2] Todd, J.V. (1961) Intramuscular Injection. British Medical Journal, 2, 1362. http://dx.doi.org/10.1136/bmj.2.5263.1362

[3] Gunn, D.R. (1964) Contracture of the Quadriceps Muscle. The Journal of Bone \& Joint Surgery, 46B, 492-497.

[4] Lloyd-Roberts, G.C. and Thomas, T.G. (1964) The Etiology of Quadriceps Contracture in Children. The Journal of Bone \& Joint Surgery, 46B, 498-502.

[5] Theodorou, S.D. (1975) Fibrosis and Contracture of the Quadriceps Muscle in Children. Acta Orthopædica Belgica, 41, 285-298.

[6] Nguyen, N.H., Do, T. and Nguyen, D.N.H. (2014) Patellar Dislocation Due to Iatrogenic Quadriceps Fibrosis: Results of Operative Treatment in 54 Cases. Journal of Children's Orthopaedics, 8, 49-59. http://dx.doi.org/10.1007/s11832-014-0564-5

[7] Hessels, G., Martens, M., Thibaut, H., Fabry, G. and Mulier, J.C. (1975) Progressive Contracture of the Quadriceps in Children. Acta Orthopædica Belgica, 41, 274-284.

[8] Malek, R. and Arama, S. (1975) Retraction Quadricepfibrosis in Childhood. Acta Orthopædica Belgica, 41, 267-273. (In French)

[9] Hung, N.N. (2009) Adduction Contracture of the Shoulder Due to Fibrous Long Head of the Triceps in Children. Journal of Children's Orthopaedics, 3, 243-249. http://dx.doi.org/10.1007/s11832-009-0176-7

[10] Chiu, S.S., Fuuya, K., Takakazu, A., Nakagawa, M. and Iida, M. (1974) Congenital Contracture of the Quadriceps Muscle. Four Case Reports in Identical Twins. The Journal of 
Bone \& Joint Surgery, 56A, 1054-1058.

[11] Faibrbank, T.J. and Barrett, A.M. (1961) Vastus Intermedius Contracture in Early Childhood. Case Report in Identical Twins. The Journal of Bone \& Joint Surgery, 43B, 326-334.

[12] Calandriello, B. and Beltrami, P. (1968) Ginocchio rigido del bambino da retrazione del quadricipite. La Chirurgia degli Organi di Movimento, 56, 427-440.

[13] Gray, J.E. (1967) Local Histologic Changes Following Long-Term Intramuscular Injections. Archives of Pathology, 84, 522-527.

[14] Goodfellow, J.W. and Nade, S. (1969) Flexion Contracture of the Shoulder Joint from Fibrosis of the Anterior Part of the Deltoid Muscle. The Journal of Bone \& Joint Surgery, 51B, 356-358.

[15] Howard, R.C. (1971) latrogenic Quadriceps and Gluteal Fibrosis. In Proceedings of The East Anglian Orthopaedic Club. The Journal of Bone \& Joint Surgery, 53B, 354.

[16] Hung, N.N. (2011) Analysis of Two Different Techniques in the Treatment of Knee Stiffness in Swing Phase Due to Fibrous Rectus Femoris Muscle in Children. Journal of Pediatric Orthopaedics B, 20, 164-179. http://dx.doi.org/10.1097/BPB.0b013e32834492fb

[17] Peiro, A., Fernandez, D.I. and Gomar, F. (1975) Gluteal Fibrosis. The Journal of Bone \& Joint Surgery, 57A, 987-990.

[18] Shanmugasundaram, T.K. (1980) Post-Injection Fibrosis of Skeletal Muscle: A Clinical Problem. International Orthopaedics, 4, 31-37. http://dx.doi.org/10.1007/BF00266601

[19] Nicoll, L.H. and Hesby, A. (2002) Intramuscular Injection: An Integrative Research Review and Guideline for Evidence-Based Practice. Applied Nursing Research, 15, 149-162. http://dx.doi.org/10.1053/apnr.2002.34142

[20] Hopkins, U. and Arias, C.Y. (2013) Large-Volume IM Injections: A Review of Best Practices. Oncology Nurse Advisor, 4, 32-37.

[21] Kundu, Z.S., Sangwan, S.S., Guliani, G., Siwach, R.C., Kamboj, P. and Singh, R. (2007) Thompson's Quadricepsplasty for Stiff Knee. Indian Journal of Orthopaedics, 41, 390-394. http://dx.doi.org/10.4103/0019-5413.37004

[22] Ikpeme, J.O. (1993) Quadricepsplasty Following Femoral Shaft Fractures. Injury, 24, 104108. http://dx.doi.org/10.1016/0020-1383(93)90199-G

[23] Hahn, S.B., Lee, W.S. and Han, D.Y. (2002) A Modified Thompson Quadricepsplasty for the Stiff Knee. The Journal of Bone \& Joint Surgery, 82B, 992-995.

[24] Crenshaw, A.H. (1998) Nontraumatic Disorders. In: Canale, S.T., Ed., Campbell s Operative Orthopaedics, 9th Edition, Mosby-Year Book, St Louis, 769-771.

[25] Paley, D. (2002) Knee Extension Contracture. Principles of Deformity Correction. Springer, Berlin, 563-569.

[26] Judet, R. (1959) Mobilization of the Stiff Knee. The Journal of Bone \& Joint Surgery, 41, 856-862.

[27] Bellemans, J., Steenwerckx, A., Brabants, K., et al. (1996) The Judet Quadricepsplasty: A Retrospective Analysis of 16 Cases. Acta Orthopædica Belgica, 62, 79-82.

[28] Daoud, H., O’Farrell, T. and Cruess, R.L. (1982) Quadricepsplasty: The Judet Technique and Results of Six Cases. The Journal of Bone \& Joint Surgery, 64B, 194-197.

[29] Ebraheim, N.A., DeTroye, R.J. and Saddemi, S.R. (1993) Results of Judet Quadricepsplasty. Journal of Orthopaedic Trauma, 7, 327-330. http://dx.doi.org/10.1097/00005131-199308000-00007

[30] Burnei, G., Petre Neagoe, P., Margineanu, B.A., Daniela, D.D. and Bucur, P.O. (2004) 
Treatment of Severe Iatrogenic Quadriceps Retraction in Children. Journal of Pediatric Orthopaedics B, 13, 254-258. http://dx.doi.org/10.1097/01.bpb.0000111028.02081.2e

[31] Moore, T.J., Harwin, C., Green, S.A., Garland, D.E. and Chandler, R.W. (1978) The Results of Quadricepsplasty on Knee Motion Following Femoral Fractures. Journal of Trauma-Injury Infection \& Critical Care, 27, 49-51. http://dx.doi.org/10.1097/00005373-198701000-00009

[32] Mukherjee, P.K. and Das, A.K. (1980) Injection Fibrosis in the Quadriceps Femoris Muscle in Children. The Journal of Bone \& Joint Surgery, 3, 453-456.

[33] Spague, R. (1982) Factors Related to Extension Lag at the Knee Joint. Journal of Orthopaedic \& Sports Physical Therapy, 3, 178-182. http://dx.doi.org/10.2519/jospt.1982.3.4.178

[34] Barreiros, H. and Goulao, J. (2014) Z-Plasty: Useful Uses in Dermatologic Surgery. Anais Brasileiros de Dermatologia, 89, 187-188. http://dx.doi.org/10.1590/abd1806-4841.20142298

[35] Wang, J.H., Zhao, J.Z. and He, Y.H. (2006) A New Treatment Strategy for Severe Arthrofibrosis of the Knee. A Review of Twenty-Two Case. The Journal of Bone \& Joint Surgery, 88, 1245-1250.

[36] Petrea, A. (2011) Iatrogenic Retraction of the Quadriceps. Jurnalul Pediatrului, XIV, 68-75.

[37] Engel, W.K. (1967) Muscle Biopsies in Neuromuscular Diseases. Pediatric Clinics of North America, 14, 963-995. http://dx.doi.org/10.1016/S0031-3955(16)32067-3

[38] Seddon, H.J. (1964) Volkmann’s Ischemia. British Medical Journal, 1, 1587-1592. http://dx.doi.org/10.1136/bmj.1.5398.1587

[39] Williams, P.F. (1968) Quadriceps Contracture. The Journal of Bone \& Joint Surgery, 50, 278-284.

[40] Bose, K. and Chong, K.C. (1976) The Clinical Manifestations and Pathomechanics of Contracture of the Extensor Mechanism of the Knee. The Journal of Bone \& Joint Surgery, 58B, 478-484.

[41] Pirola, E., Hébert-Blouin, M.N., Amador, N., et al (2009) Palmaris Profundus: One Name, Several Subtypes, and a Shared Potential for Nerve Compression. Clinical Anatomy, 22, 643-648. http://dx.doi.org/10.1002/ca.20848

[42] Robinson, D., Aghasi, M.K. and Halperin, N. (1989) Ulnar Tunnel Syndrome Caused by an Accessory Palmaris Muscle. Orthopedic Reviews, 18, 345-347.

[43] Gordon, S.L. and Matheson, D.W. (1973) The Accessory Soleus Muscle. Clinical Orthopaedics and Related Research, 97, 129-132.

[44] Romanus, B., Lindahl, S. and Stener, B. (1986) Accessory Soleus Muscle: A Clinical and Radiographic Presentation of Eleven Cases. The Journal of Bone \& Joint Surgery, 68A, 731734.

[45] Kouvalchouk, J.F., Lecocq, J., Parier, J. and Fischer, M. (2005) The Accessory Soleus Muscle: A Report of 21 Cases and a Review of the Literature. Revue de Chirurgie Orthopédique et Réparatrice de l'Appareil Moteur, 91, 232-238. (In French) http://dx.doi.org/10.1016/S0035-1040(05)84309-0

[46] Labbé, J.L., Peres, O., Leclair, O., Scemama, P., Jourdel, F. and Duparc, B. (2011) Progressive Limitation of Knee Flexion Secondary to an Accessory Quinticeps Femoris Muscle in a Child: A Case Report and Literature Review. The Journal of Bone \& Joint Surgery, 93B, 1568-1570. http://dx.doi.org/10.1302/0301-620X.93B11.27396

[47] Warner, J.J. (1990) The Judet Quadricepsplasty for Management of Severe Posttraumatic Extension Contracture of the Knee: A Report of a Bilateral Case and Review of the Litera- 
ture. Clinical Orthopaedics and Related Research, 256, 169-173.

[48] Thompson, T.C. (1944) Quadricepsplasty to Improve Knee Function. The Journal of Bone \& Joint Surgery, 26, 366-379.

[49] Hesketh, K.T. (1963) Experiences with the Thompson quadricepsplasty. The Journal of Bone \& Joint Surgery, 45B, 491-495.

[50] Ratliff, A.H.C. (1972) Quadricepsplasty. Injury, 4, 126-130. http://dx.doi.org/10.1016/0020-1383(72)90010-1

[51] Pick, R.Y. (1976) Quadricepsplasty: A Review, Case Presentations, and Discussion. Clinical Orthopaedics and Related Research, No. 120, 138-142.

[52] Fiogbe, M.A., Gbenou, A.S., Magnidet, E.R. and Biaou, O. (2013) Distal Quadricepsplasty in Children: 88 Cases of Retractile Fibrosis Following Intramuscular Injections Treated in Benin. Orthopaedics \& Traumatology. Surgery \& Research, 99, 817-822. http://dx.doi.org/10.1016/j.otsr.2013.04.014

[53] Alvares, E.V., Munters, M., Lavine, L.S., Manes, H. and Waxman, J. (1980) Quadriceps Myofibrosis. A Complication of Intramuscular Injection. The Journal of Bone \& Joint Surgery, 62A, 58-60.

[54] Jackson, A.M. and Hutfon, P.A. (1985) Injection-Induced Contractures of the Quadriceps in Childhood. A Comparison of Proximal Releasae and Distal Quadricepsplasty. The Journal of Bone \& Joint Surgery, 67B, 97-102.

[55] Gbenou, A.S., Kpadonou, G.T., Fiogbe, A.M., Zoumenou, E. and Alao, M.J. (2013) Iatrogenic Retractile Quadriceps Fibrosis within Children in Benin: Epidemiological, Clinical, Therapeutical Aspects. African Journal of Paediatric Surgery, 10, 211-216. http://dx.doi.org/10.4103/0189-6725.120877

[56] Wang, J.H., Zhao, J.Z. and Yao, H.H. (2006) A New Treatment Strategy for Severe Arthrofibrosis of the Knee: A Review of Twenty-Two Cases. The Journal of Bone \& Joint Surgery, 88A, 1245-1250. http://dx.doi.org/10.2106/JBJS.E.00646

[57] Goldthwait, J.E. (1897) The Direct Transplantation of Muscles in the Treatment of Paralytic Deformities. The Journal of Bone \& Joint Surgery, 110, 246-252.

[58] Pritsch, T., Malawer, M.M., Wu, C.C., Squires, M.H. and Bickels, J. (2007) Functional Reconstruction of the Extensor Mechanism Following Massive Tumor Resections from the Anterior Compartment of the Thigh. Plastic \& Reconstructive Surgery, 120, 960-969. http://dx.doi.org/10.1097/01.prs.0000256477.01388.de

[59] Kuhlmann, R.F. and Bell, J.F. (1952) A Clinical Evaluation of Tendon Transplantation for Poliomyelitis Affecting the Lower Extremities. The Journal of Bone \& Joint Surgery, 34A, 915-926.

[60] Prada, S.A., Griffin, F.M., Nelson, C.L. and Garvin, K.L. (2003) Allograft Reconstruction for Extensor Mechanism Rupture after Total Knee Arthroplasty: 4.8-Year Follow-Up. Orthopedics, 26, 1205-1208.

[61] Ober, F.R. (1933) Tendon Transplantation in the Lower Extremity. The New England Journal of Medicine, 209, 52-59. http://dx.doi.org/10.1056/NEJM193307132090202

[62] Spifzy, H. (1924) Neue operative Wege in der orthopadischen Chirurgie. Wiener Medizinische Wochenschrift, 27, 1406-1413.

[63] Spifzy, H. (1925) Natiirliche und kiinstliche Bandmuskelbildung. Zeitschr. Orthop. Chir, 46, 111-118.

[64] Erlacher, P. (1955) Lehrbuch der praktischen Orthopadie. Wien-Bonn.

[65] Yount, C.C. (1926) The Role of the Tensor Fasciae Femoris in Certain Deformities of the 
Lower Extremities. The Journal of Bone \& Joint Surgery, 8, 171-178.

[66] Younf, C.C. (1938) An Operation to Improve Function in Quadriceps Paralysis. The Journal of Bone \& Joint Surgery, 20, 314-320.

[67] Broderick, T.F., Reidy, J.A. and Burr, J.S. (1952) Tendon Transplantations in the Lower Extremity. A Review of End Results in Poliomyelitis. II. Tendon Transplantations at the Knee. The Journal of Bone \& Joint Surgery, 34A, 909-914.

[68] Storen, H. (1957) Some Experiences of Transposition of the Hamstrings in Paralysis after Anterior Poliomyelitis. Acta Orthopaedica Scandinavica, 26, 282-287.

[69] Debrunner, H. (1940) Die Behandlung der Quadricepslahmung. Zeitschr. Orthop, 70, 164-169.

[70] Abtullah, M., Metin, M.E. and Öztuna, V. (2004) Injection-Induced Contracture of the Quadriceps Femoris Muscle in Children. Orthopedics, 27, 65-66.

[71] Shivaprasad, M., Yashavantha, K., Ravikumar, T. and Shreel, K. (2015) Surgical Management of Quadriceps Contracture. International Journal of Science and Research (IJSR), 4, 1919-1922.

[72] Ali, A.M., Villafurete, J., Hashmi, M. and Saleh, M. (2003) Judet's Quadricepsplasty, Surgical Technique and Results in Limb Reconstruction. Clinical Orthopaedics and Related Research, 415, 214-220.

[73] Muteti, E.N., Theuri, J.T., Mead, T.C. and Gokcen, E.C. (2009) Results of Surgical Treatment of Quadriceps Femoris/Contracture in Children. East African Orthopaedic Journal, 3, 69-72.

Submit or recommend next manuscript to OALib Journal and we will provide best service for you:

- Publication frequency: Monthly

- 9 subject areas of science, technology and medicine

- Fair and rigorous peer-review system

- Fast publication process

- Article promotion in various social networking sites (LinkedIn, Facebook, Twitter, etc.)

- Maximum dissemination of your research work

Submit Your Paper Online: Click Here to Submit

Or Contact service@oalib.com 